$\mathrm{F}$ - aged sixty-seven. He found her in bed in the apoplectic condition. There was total loss of consciousness, the pupils were fixed, but there was slight reflex action on touching the eyeball, the face was turgid, the cheeks were puffed out on expiration, and there was deep pharyngeal stertor. On being placed on her side the stertor ceased and ghe gradually improved. In twelve hours she had perfectly recovered consciousness, the respiration was normal, the face very pale, the pulse quick and feeble; there was no paralysis. The action of the heart was feeble, but there was no murmur.

CASE 8.- I was called in August, 1859, to a boy who had fallen on his head from a height. I found him lying on his back snoring, senseless, and collapsed; pulse irregular and pupils alternately contracting and dilating. The mouth was half full of vomited matter. On turning him on his side the snoring (palatine stertor) ceased, he was sick several times with comparative ease. Presently he began snoring whilst he was on his side, his chin was bent upon the sternum; on straightening the neck he was quiet. The boy slowly recovered. On three different occasions in my own practice I have been summoned to cases of apoplexy with stertor, in which the patients recovered, two with and one without paralysis.

Case 4 demonstrates that as power returns to the brain the pneumogastric and probably also the sympathetic regain their power, and effusion into the lung ceases; and, moreover, that the lung is not injured by remaining inactive and filled with mucus for a long period.

(To be concluded.)

\section{NOTE ON THE DIAGNOSIS OF CAVITY IN THE LUNG.}

\section{BY SOLOMON CHARLES SMITH} SURGEOY TO THE HATIFAX INFIRMARY.

I HAVE recently met with a peculiar physical sign of deepseated cavity in the lung, of which I can find no mention in any of the books within my reach, and which seems worthy of being placed on record. It is a sound synchronous with the cardiac systole; not necessarily heard over the lung, but distinctly audible in the trachea, and even without the stethoscope when merely standing opposite the patient, and obviously produced by the impact of the contracting ventricle against a neighbouring cavity, expelling such a puff of air as to produce a sound in the bronchus and trachea.

My first patient was a man suffering from cough, expectoration, and shortness of breath. While watching the expansion of his lungs I heard a bruit synchronous with the first sound of the heart; it was short and soft, but plainly audible when we were about eighteen inches apart. On applying the stethoscope over the heart nothing abnormal was heard, but over the lung to the left the bruit was easily perceived. Systolic bruit over the left upper lobe is, how. ever, no strange thing in phthisis, but on tracing it up it was loudly audible in the trachea, and on careful observation it was plain that the sound was conveyed ontwards through the air-passages. Easy respiration did not interfere with its production, but on breathing deeply or quickly it was interrupted during inspiration.

The other physical signs were dulness, diminished respiration, and expansion, with moist clicks over the upper five inches of the left lung, and some tubular cough sound at the third interspace.

In my next case the physical sign $I$ have described was not so well marked-that is, it was more easily interrupted by inspiration, and could not be heard quite so far from the patient; but, on the other hand, its connexion with a cavity was more completely demonstrated, the presence of a vomica being proved by a concurrence of many physical signs.

$I$ do not at all wish to add another to the many sounds which have been described as occurring in cavities in the lung; if this were audible only over the position of the vomica it would be a matter of no great interest. Any importance it may possess arises from its being transmitted to the ear through the air-passages rather than through the chest walls, and thus being audible even when the disease is deeply placed. I may add that in auscultation of the trachea and larynx a flexible stethoscope is of great service.

Halifax.

\section{AN UNUSUAL CASE OF CONGENITAL SYPHILIS.}

\author{
BY M. PRICKETT, M.D.
}

THE following case appears to me of so much interest both from its rarity and its importance as to deserve publication; especially so as I am unable to find any records of precisely similar symptoms.

Mr. - contracted syphilis three years ago ; a chancre developed, and in due course of time mild secondary symptoms followed. These soon disappeared under treatment, which was continued for about six weeks, and the disease appeared eradicated. He remained in good health until his marriage a year ago; shortly after which, however, a skin eruption of doubtful nature developed itself. This was treated without avail by a large variety of remedies, amongst which were mercury and iodide of potassium; but I am unable to learn how long they were persevered with. As the eruption got considerably worse a specialist was consulted, who pronounced the disease to be psoriasis, but of a non-specific character. In spite of his treatment the eruption spread until, three months ago, his legs and arms were covered with it and patches also appeared upon the trunk.

About a year after his marriage Mrs. — was confined with a female child under my care; the labour was natural and easy and the mother recovered without developing any symptoms of syphilitic infection.

The infant appeared perfectly healthy and was suckled by its mother; it fed regularly, the motions were normal in colour and frequency, and it slept soundly. On the night of the fourteenth day after birth it refused the breast and was observed by the nurse to be drowsy and feeble; at I A.M. she found it cold, blue, and gasping for breath. When I arrived an hour later it was in a state of semi-collapse, dusky, pulse running and almost imperceptible, and so weak it could scarcely cry or move. The temperature was $99.5^{\circ}$. It was ordered some brandy and a warm bath. Next morning a few mulberry-colonred spots were visible on the face, arms, and buttocks, which did not fade on pressure and were scarcely raised above the surface, but became as the day passed darker in colour and more prominent. Some fresh spots also appeared upon the legs. The temperature was now $102^{\circ}$; the child had been sick several times and the motions were somewhat slimy; otherwise the child appeared better; the pulse was stronger and skin less dusky. 1 Suspecting that the child might be suffering from variola, it was weaned and separated from the mother for the next three days. The child rapidly improved in its condition, but the spots, about ten in number, grew hard, raised, and black, much resembling the spots of hæmorrhagic variola. In about three days time it appeared quite well, the spots remaining as before.

On the fifth day after the first attack it was seized in the same way again. It became rigid, cold, dusky, the respirations became gasping, and, according to its nurse, "it seemed convulsed." When I saw it about an hour afterwards it had partially recovered; the heart sounds were normal and so was the temperature. It fed as usual and the motions were healthy. It was ordered bromide of potassium and ammonia together with a little brandy at short intervals. In the night it had two or three similar attacks followed by much larger extravasations of blood beneath the skin. The next morning it was much weaker; it could scarcely cry, and did not take notice of anything about it, although it continued to take its food regularly and the motions remained healthy. The subcutaneous extravasations, three or four in number, took the form of bluish rounded lumps about one and a half inches in diameter, and there were also some small petechiæ upon the legs and buttocks.

From this time the child gradually sank ; cerebral respiration supervened, and it died on the fourth day of the second attack.

No post-mortem examination was made. The child was never treated mercurially because the syphilitic character of the disease was not suspected, partly owing to my not being aware at the time of the father's previous history, nor of the existence of his skin affection, and partly to my ignorance of I Careful examination of the heart elicited no signs of disease what-
erer, 